\title{
A longitudinal assessment of the diet and growth of malnourished children participating in nutrition rehabilitation centres in Accra, Ghana
}

\author{
Esi K Colecraft ${ }^{1}$, Grace S Marquis ${ }^{1}{ }^{*}$, Alfred A Bartolucci ${ }^{2}$, LeaVonne Pulley ${ }^{3}$, \\ W Bruce Owusu ${ }^{4}$ and $\mathrm{H}$ Michael Maetz ${ }^{5}$ \\ 'Department of Food Science and Human Nutrition, 1127 HNSB, lowa State University, Ames, IA 50014, USA: \\ ${ }^{2}$ Department of Biostatistics, School of Public Health, University of Alabama at Birmingham, USA: ${ }^{3}$ Department of \\ Health Behaviour, School of Public Health, University of Alabama at Birmingham, USA: ${ }^{4}$ Department of Nutrition and \\ Food Science, University of Ghana, Legon, Ghana: ${ }^{5}$ Department of Epidemiology, School of Public Health, \\ University of Alabama at Birmingham, USA
}

Submitted 19 August 2003: Accepted 13 0ctober 2003

\begin{abstract}
Objective: To examine the adoption of feeding recommendations among caregivers of children recuperating from malnutrition and assess the determinants of growth of children attending a nutrition rehabilitation centre (NRC) in Accra, Ghana.

Design: Longitudinal study in which attendance and maternal programme participation were recorded daily and children's anthropometry and dietary intake were measured at four time points (admission, interim, exit, post-exit) at the NRC and participants' homes.

Setting: NRCs at four polyclinics and participants' homes in Accra, Ghana.

Subjects: One hundred and eight caregivers and their 116 children referred to an NRC between November 1999 and July 2000.

Results: Most caregivers attended the NRC sporadically (effective length of stay was $1.4 \pm 0.1$ months). Use of NRC-promoted foods in the home after discharge was low due to inaccessibility of the food items, lack of preparation knowledge or money, child preferences and the common practice of purchasing ready-to-eat foods. Although there were significant increases in children's weight-for-age $(P=0.048)$ and weight-for-height $(P=0.002) Z$-scores between enrolment and discharge, most children discontinued programme participation before adequate recuperation.

Conclusions: The NRC education did not address the use of street foods for child feeding and was unsuccessful in changing in-home feeding behaviour. The prominence of street foods in children's diets warrants re-evaluation of the NRC's educational approaches to enhance their responsiveness to caregivers' needs and effectiveness for the continued recuperation of malnourished children at home. NRC feeding strategies need improvement to ensure adequate provision of energy and nutrients to support catch-up growth in children.
\end{abstract}

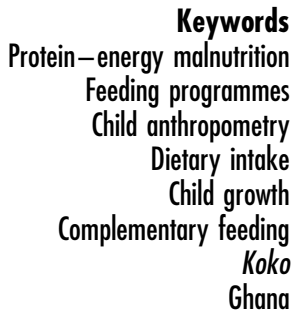

Protein-energy malnutrition (PEM) is a problem of public health significance in most developing countries and is associated with increased childhood morbidity and mortality $^{1,2}$. In Ghana, about $40 \%$ of all child deaths beyond infancy are due to PEM, making it the greatest single cause of child mortality ${ }^{3}$. With approximately onequarter of Ghanaian children either underweight or stunted $^{4}$, Ghana is classified in the medium to high range of severity of malnutrition in a population ${ }^{5}$.

The debilitating effects of malnutrition have prompted initiatives to improve children's nutritional well-being. In the mid-1950s, Bengoa proposed the nutrition rehabilitation centre (NRC) as a strategy for combating childhood
$\mathrm{PEM}^{6}$. This system was piloted in Ghana in the $1970 \mathrm{~s}^{7}$ and later integrated into primary healthcare facilities (polyclinics) throughout the country. Presently, the centres are operated as day-care facilities where malnourished children attend daily with their caregivers. The programme objectives are to recuperate malnourished children through supplemental feeding and to educate caregivers on optimal feeding practices through participation in food preparation activities.

The NRC programme in Ghana has not been systematically evaluated to determine its effectiveness. Evaluations of NRC programmes in other settings have reported mixed results ${ }^{8-11}$. Many of these studies are now dated 
and the paucity of recent information on NRC programmes may suggest that the popularity of these programmes has waned. However, an NRC programme has been implemented in northern Brazil in recent years ${ }^{12}$ and they are still operational in Ghana and other countries.

Evaluation of ongoing NRC activities can identify programme gaps to inform policy directives for programme improvement or new initiatives. We conducted an evaluation study of the NRC programme in Accra, Ghana. In this paper we report on caregivers' programme participation and changes in children's growth during and after NRC participation. We also examine whether there were longitudinal changes in children's home-based diets that reflect caregivers' adoption of child-feeding practices promoted by the NRC. This examines the underlying premise of the NRC: that caregivers' active participation in programme activities leads to adoption of NRC recommendations.

\section{Methods}

\section{Study sites}

At the time of the study, there were four Accra polyclinics with a functioning day-care NRC. These study sites are referred to as NRC 1 to 4 . Participation in the NRC was by referral by healthcare workers because of a clinical diagnosis of malnutrition, poor weight gain or perceived risk of malnutrition. Caregivers were expected to attend the NRC with their children 5 days a week from 09.00 to 14.00 .

\section{Study participants}

All caregiver/child pairs who were newly enrolled in an NRC between November 1999 and July 2000 were recruited within 2 days of NRC enrolment. The criteria for participation were (1) the attendee was the child's primary caregiver, (2) residence in the NRC's catchment area and (3) willingness to participate. Written informed consent was obtained with a signature or thumbprint.

A total of 129 caregivers with their 136 children (including five sets of twins and one set of triplets) were invited to participate (Fig. 1). Five caregivers refused participation because they did not intend to continue attending the NRC. Another 16 caregivers agreed to participate but only attended the NRC for one day and did not complete the data collection process at enrolment. Complete data records were obtained for 108 caregivers and 116 children at enrolment. Reasons for loss to followup included $<10$ days of attendance with no data at the interim time point $(n=36)$, migration $(n=8)$, unavailable for home visits after three attempts $(n=8)$, still enrolled in the NRC at the end of the study $(n=3)$, caregiver refused the final follow-up visit $(n=3)$ and child's death $(n=11)$. Of the children who died between admission and interim $(n=7)$, two died at the children's hospital after being referred there a few days after enrolment. Two of the deaths between interim and exit

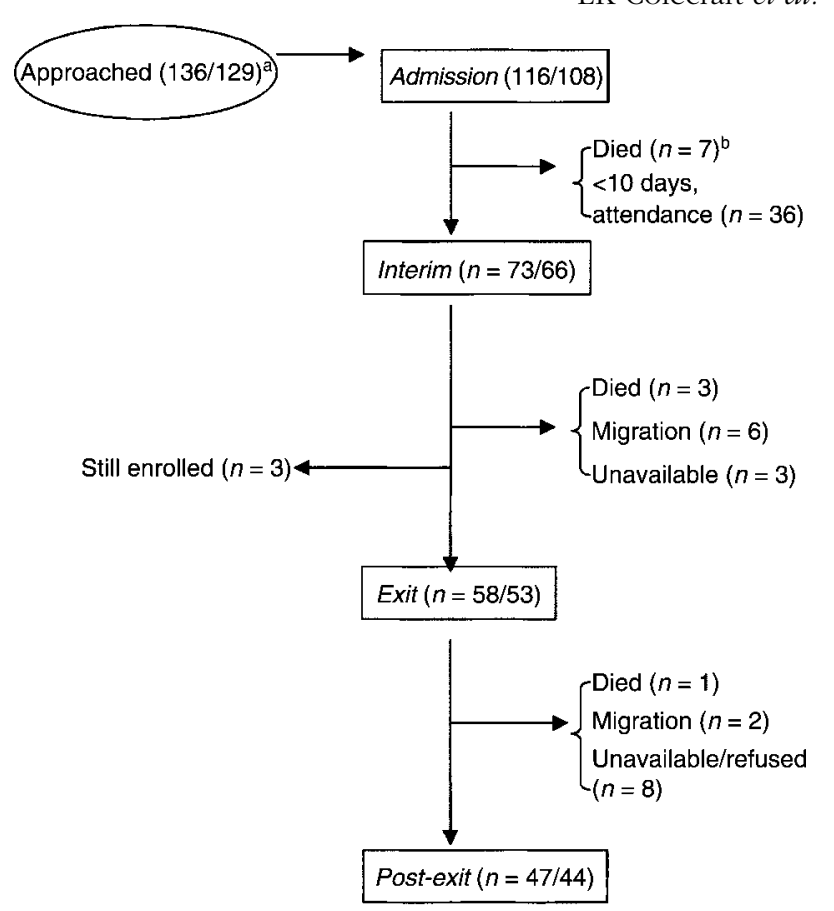

aNumber of children/number of caregivers

bNumber of children

Fig. 1 Sampling profile demonstrating the number of Ghanaian women and children enrolled, reasons for exclusion and number of mother/child pairs followed at different time points

were suspected HIV-related deaths. Between interim and exit, and exit and post-exit, one death was attributed to the caregiver's decision to use traditional healers rather than the health services.

\section{Data collection}

The caregivers and children were followed while at the NRC and for up to 4 months after leaving the programme. Family demographic and socio-economic information was obtained at enrolment. Children's health status (diagnosis of malaria, diarrhoea, upper and lower respiratory tract infections) and birth date were obtained from clinic records. Data were collected through observations and semi-structured interviews each weekday at the NRC and during three home visits. To minimise changes in routine feeding practices, caregivers were given a 3-day time frame in which to expect a visit. Four specific time points were of interest for this analysis: enrolment (admission), after 10 days of NRC participation (interim), voluntary or official discharge from the NRC (exit) and 2-4 months after leaving the NRC (post-exit). House location for home visits occurred when caregivers achieved 10 days of NRC attendance; therefore caregivers who attended for fewer than 10 days could not be followed further.

\section{Daily activities at the NRC and child bealth}

Fieldworkers maintained a daily (Monday to Friday) NRC attendance record for each participant, recording what 
meals (breakfast, lunch, snack) were prepared, and caregiver's level of participation in each meal. Additionally, caregivers reported whether their children had diarrhoea, fever, irritability and anorexia.

\section{Antbropometry and dietary intake}

Weight and length (or height if $>24$ months) were taken at the four time points. Children were weighed without clothes to the nearest $0.1 \mathrm{~kg}$ with Salter hanging scales (model 235 6S; Salter, West Midlands, UK) that were calibrated daily. Length or height was measured to the nearest $0.1 \mathrm{~cm}$ with locally made wooden stadiometers. Anthropometric measurements were taken in triplicate and the mean was recorded.

Dietary information was obtained by 24-hour dietary recall interviews ${ }^{13}$, with probing, at admission, exit and post-exit. Fieldworkers recorded the major ingredients in the foods named and the source (whether home-made, purchased ready-to-eat from street vendors or prepared at the NRC). An eating event was defined as a meal, snack or beverage besides water and breast milk. Breast milk was excluded because the NRC focus was to improve complementary feeding; however, children were classified as still breast-fed or weaned. Caregivers were interviewed about NRC foods and the feasibility of incorporating NRC practices into the home diet. The interviews were taperecorded.

\section{Data analysis}

Statistical analyses were performed using the SAS system for Windows version 8 (SAS Institute, Cary, NC, USA). Weights and lengths/heights were converted into weightfor-age (WAZ), weight-for-height (WHZ) and height-forage (HAZ) $Z$-scores using Epi-Info version 6.0 (Centers for Disease Control and Prevention, Atlanta, GA, USA). Use of NRC-promoted foods in the home diet was an indication of adoption of NRC recommendations. Outcomes were compared between NRC locations because of centre differences in the delivery of services. Categorical comparisons were tested with the chi-square statistic and one-way analysis of variance (ANOVA) was used to assess centre differences for continuous variables. Other analyses controlled for NRC location. The Mantel-Haenszel chisquare statistical test for repeated measures was used to assess longitudinal changes in the use of promoted food items. Longitudinal differences in the sources of foods and change in anthropometric indices were tested with repeated-measures ANOVA and Bonferonni post hoc tests.

Change in each anthropometric outcome between admission and exit and between exit and post-exit was categorised as 'improvement' or 'no improvement' for each index. The Mantel-Haenszel chi-square statistic was then used to identify factors significantly associated with improved anthropometry between admission and exit and between exit and post-exit. Continuous variables such as length of programme participation and effective stay (defined as the product of the length of programme participation and the proportion of days attended ${ }^{8}$ ) were converted to dichotomous variables (above and below the mean values). All variables that were significant in these bivariate analyses, as well as child and caregiver characteristics, child morbidity during NRC participation and caregiver's participation in NRC activities, were included in linear regression equations to predict each anthropometric outcome at exit and post-exit. Variable selection in the regression models was set at $P \leq 0.1$.

The qualitative interviews with caregivers were translated into English. Each interview was translated first by the fieldworker who conducted the interview and then by the first author (E.K.C.) or a second fieldworker. The two translations were compared and inconsistencies addressed. The translated interviews were reviewed using cross-case analysis ${ }^{14}$. Important themes with accompanying quotes were abstracted and summarised.

\section{Etbics}

Approval for the study was obtained from the Institutional Review Boards at the University of Alabama at Birmingham and Iowa State University and from the Ghana Ministry of Health.

\section{Results}

\section{Overview of the NRC programme}

The NRC supplementary feeding programme included breakfast and lunch; two centres offered a mid-morning snack. Caregiver education occurred through participation in preparing meals. The NRC used a diversity of cereals and cereal mixes as nutritious alternatives for preparing traditional corn-based foods, fish powder and/or soybean flour as inexpensive protein sources, and green leafy vegetables. The main cereals used were sorghum, wheatsoy blend (WSB) and Weanimix (a blend of roasted and milled cereal, legume and groundnuts, 8:1:1, prepared at the NRC).

\section{Child characteristics at admission}

At admission, the children's age was $12.7 \pm 0.5$ months (Table 1). Approximately two-thirds were still breastfeeding; none of the children aged below 6 months were exclusively breast-fed. There were no significant centre differences in children's age, gender or breast-feeding status.

The majority of children were underweight. There were no significant centre differences in the rates of wasting and underweight; however, children referred to NRC 1 and 4 were significantly more likely to be stunted than those referred to NRC 2 and $3(P=0.004)$.

The diarrhoeal prevalence rate at admission at NRC 1 was half the rate at NRC 2 and 4, and one-quarter that of NRC 3. Respiratory tract infections were significantly more prevalent in children recruited from NRC 4 compared with 
Table 1 Demographic and health characteristics of the Ghanaian children at the time of admission to the four nutrition rehabilitation centres (NRCs)

\begin{tabular}{|c|c|c|c|c|c|}
\hline \multirow[b]{2}{*}{ Characteristic } & \multicolumn{5}{|c|}{ NRC location } \\
\hline & $1(n=12)$ & $2(n=33)$ & $3(n=49)$ & $4(n=22)$ & $\begin{array}{c}\text { Overall } \\
(n=116)\end{array}$ \\
\hline Age (months) & $10.6 \pm 1.2^{*}$ & $12.0 \pm 1.1$ & $13.8 \pm 0.7$ & $12.3 \pm 0.9$ & $12.7 \pm 0.5$ \\
\hline$<6$ & $16.7 \dagger$ & 16.7 & 0.0 & 4.8 & 7.1 \\
\hline 6 to $<12$ & 58.3 & 36.7 & 40.8 & 52.4 & 43.8 \\
\hline 12 to $<18$ & 16.7 & 33.3 & 46.9 & 28.6 & 36.6 \\
\hline 18 to $<24$ & 8.3 & 6.7 & 8.2 & 14.3 & 3.8 \\
\hline$\geq 24$ & 0.0 & 6.7 & 4.0 & 0.0 & 3.8 \\
\hline \multicolumn{6}{|l|}{ Gender } \\
\hline Male & 41.7 & 33.3 & 38.8 & 59.1 & 41.4 \\
\hline Female & 58.3 & 66.7 & 61.2 & 40.9 & 58.6 \\
\hline Still breast-feeding & 83.3 & 60.6 & 77.6 & 59.1 & 69.8 \\
\hline \multicolumn{6}{|l|}{ Anthropometry } \\
\hline WHZ $<-2.00$ (wasted) & 50.0 & 48.5 & 65.3 & 59.1 & 57.8 \\
\hline WAZ $<-2.00$ (underweight) & 83.3 & 84.9 & 93.9 & 100.0 & 91.4 \\
\hline $\mathrm{HAZ}<-2.00$ (stunted) $\ddagger$ & 75.0 & 57.6 & 42.9 & 86.4 & 58.6 \\
\hline Diarrhoeał & 8.3 & 18.2 & 44.9 & 18.2 & 28.5 \\
\hline Upper or lower respiratory tract infection $\ddagger$ & 0.0 & 9.1 & 0.0 & 50.0 & 12.1 \\
\hline Malariał & 8.3 & 33.3 & 2.0 & 9.0 & 11.2 \\
\hline
\end{tabular}

the other centres. Children recruited from NRC 2 were more likely to be diagnosed with malaria than those from the other sites $(P<0.05)$.

\section{Programme exposure}

The duration of NRC participation (admission to exit) was $4.0 \pm 0.2$ months; however, attendance was sporadic. Effective stay, accounting for missed days, was a more accurate indicator of the level of programme exposure. The effective stay was $1.4 \pm 0.1$ months. Caregivers from NRC 3 had a significantly lower effective stay than did caregivers from NRC $2(1.1 \pm 0.1$ vs. $1.7 \pm 0.2$ months, respectively; $P<0.05$ ). Only $22 \%$ of the caregiver/child pairs were officially discharged from the programme; the remainder stopped attending on their own. There were no significant differences in sociodemographic, nutrition and health characteristics at admission between caregivers and children who dropped out and those who continued NRC attendance.

\section{Changes in the children's diet}

Dietary data were available for at least $89 \%$ of the children at each time point. Approximately $25 \%$ of eating events at admission comprised NRC-prepared foods because recruitment occurred within 2 days of enrolment into the programme (Fig. 2). The proportion of home-made eating events was highest at the time of exit $(65.0 \pm 3.4 \%)$ and decreased significantly between exit and post-exit (to $49.0 \pm 4.1 \% ; P<0.01)$. Purchased foods in the children's diets increased $(P<0.001)$ progressively from admission $(24.1 \pm 2.7 \%)$ to post-exit $(48.6 \pm 4.1 \%)$.

An NRC programme objective was the use of a variety of grains to diversify the traditional corn-based diet. After controlling for NRC-prepared foods, there were no significant longitudinal differences in children's consumption of corn; at each time point, at least two-thirds of eating events contained corn (Table 2). There were no longitudinal differences in the consumption of sorghum, WSB or Weanimix. Consumption of other grains, primarily millet, decreased significantly from admission to post-exit $(P=0.031)$.

Caregivers used protein sources other than those promoted at the NRC. At each time point, approximately $50 \%$ of eating events contained animal protein other than fish powder. There were no differences in the

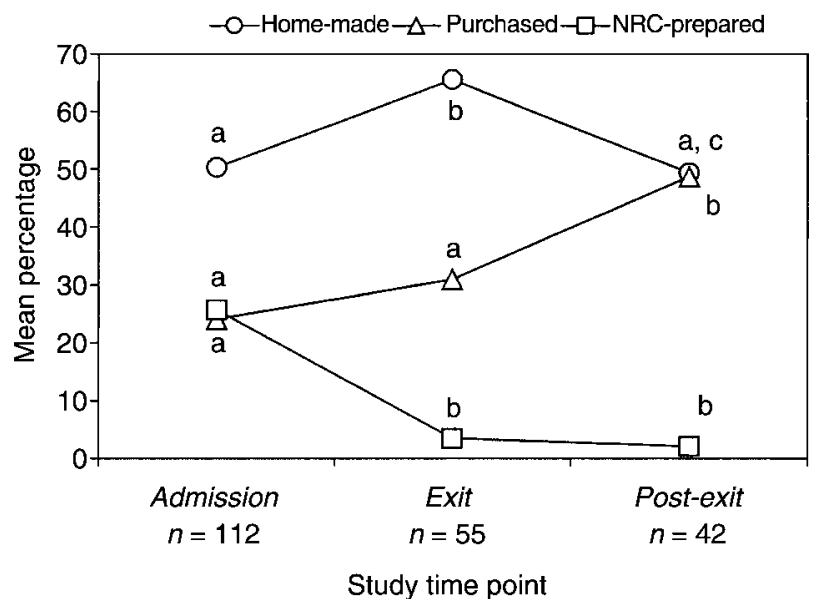

Fig. 2 Use of different preparation sites for obtaining food for Ghanaian children participating in nutrition rehabilitation centres (NRCs), by study time point. Means on a line with different superscripts are significantly different $(P<0.05)$; using one-way analysis of variance and Bonferonni's post hoc comparisons between time points. Incomplete dietary data for four, three and five children at admission, exit and post-exit, respectively 
Table 2 Proportion of eating events containing cereals, protein sources and green leafy vegetables among Ghanaian children participating in nutritional rehabilitation centres (NRCs), by study time point

\begin{tabular}{|c|c|c|c|c|}
\hline & $\begin{array}{c}\text { Admission } \\
(n=112)^{\star}(\%)\end{array}$ & $\begin{array}{c}\text { Exit } \\
(n=55)(\%)\end{array}$ & $\begin{array}{c}\text { Post-exit } \\
(n=42)(\%)\end{array}$ & $P$-value $\dagger$ \\
\hline \multicolumn{5}{|l|}{ Cereals/cereal mixes } \\
\hline Corn & 66.1 & 72.7 & 76.2 & 0.375 \\
\hline Sorghum & 44.6 & 29.1 & 16.7 & 0.879 \\
\hline Wheat-soy blend & 16.1 & 18.2 & 2.4 & 0.311 \\
\hline Weanimix & 16.1 & 0.0 & 2.4 & 0.392 \\
\hline Otherł & 15.8 & 20.6 & 34.7 & 0.031 \\
\hline \multicolumn{5}{|l|}{ Protein sources } \\
\hline Fish powder & 24.1 & 23.6 & 14.3 & 0.652 \\
\hline Other animal protein & 49.1 & 58.2 & 50.0 & 0.839 \\
\hline Soybean flour & 15.2 & 18.2 & 11.9 & 0.788 \\
\hline Other plant protein§ & 19.6 & 43.6 & 64.3 & 0.004 \\
\hline Milk & 39.3 & 25.5 & 11.9 & 0.007 \\
\hline Eggs & 18.7 & 14.6 & 4.8 & 0.236 \\
\hline \multicolumn{5}{|l|}{ Vegetables } \\
\hline Leafy green vegetables & 13.4 & 23.6 & 38.1 & 0.236 \\
\hline
\end{tabular}

* Incomplete dietary data for four, three and five children at admission, exit and post-exit, respectively.

† Significance associated with chi-square test for repeated measures after controlling for eating events that were NRC-prepared foods.

$\ddagger$ Other cereals consumed were millet, rice and oats.

$\S$ Other plant proteins included cowpeas and bambara beans.

consumption of fish powder over time. Less than $20 \%$ of eating events at each time point contained soybean powder. Use of other plant proteins (mostly cowpeas) in children's foods increased between admission and postexit $(P=0.004)$. Consumption of milk decreased significantly from admission to post-exit $(P=0.007)$. There were no longitudinal differences in the consumption of green leafy vegetables.

\section{Caregivers' perceptions on barriers to adoption of NRC foods}

Caregivers indicated that inaccessibility of NRC foods, lack of preparation knowledge and money, and child preferences prevented their adoption of NRC feeding practices. Caregivers referred mostly to the cereals used at the centres as inaccessible, saying 'I don't know where to get the sorghum and tom-brown [wheat-soy blend]... they used to give us some at the clinic but since I stopped going there I have not been able to get any.' Caregivers also reported not knowing how to prepare the NRC foods because they had been unable to participate in the food preparation activities. According to one caregiver, 'When I was going to the centre, the twins' mother would always get to the centre before me and would have already started the cooking. So, by the time I got to the NRC, I would only see the end part of the cooking so I don't know how to cook the same way.'

Lack of money was considered a constraint to cooking in general; a few caregivers stated that NRC recommendations would cost more than they normally spent on food. 'If someone doesn't have money she can't cook like they did at the NRC. Me personally, I don't want to push myself to do something that I can't keep up with for my son because the day I won't have the money to do it, it will be a problem.' These caregivers considered buying ready-to-eat meals from street vendors as a cheaper alternative to home cooking. 'Sometimes when I compare what I can cook with the money I have to what I can buy already prepared from outside, I can get more by buying the already cooked food from the roadside.'

Children's poor appetite and/or taste preferences coupled with caregivers' perceptions that adopting NRC recommendations would require them to cook separately for their children were other constraints to adopting NRC recommendations. 'I used to buy fish powder when I took my child to the clinic for weighing and I would use it to cook for him. But he generally doesn't like to eat so it's a waste of time to cook things for him separately.' Another shared sentiment was 'Whenever I make Weanimix my children refuse to eat it. They prefer the already prepared $k o k o$ [cereal-based porridge] that I buy from outside so that is what I give to them.'

\section{Child growtb}

There were no significant longitudinal differences in anthropometry between the four centres despite differences in stunting and morbidity at admission. WHZ and WAZ at admission were $-2.13 \pm 0.07$ and $-3.25 \pm 1.01$, respectively, and $-1.62 \pm 0.11$ and $-2.83 \pm 0.13$, respectively, at exit (Fig. 3). This gave significant but small increases of 0.51 and $0.42 Z$-scores in WHZ and WAZ, respectively $(P<0.05)$. There were no further significant increases in WHZ and WAZ between exit and post-exit. There was no longitudinal change in HAZ and it remained below -2 for all time points.

\section{Factors associated with children's anthropometric outcomes}

Children with longer effective stay were more likely to have increased WHZ and WAZ between admission and exit 


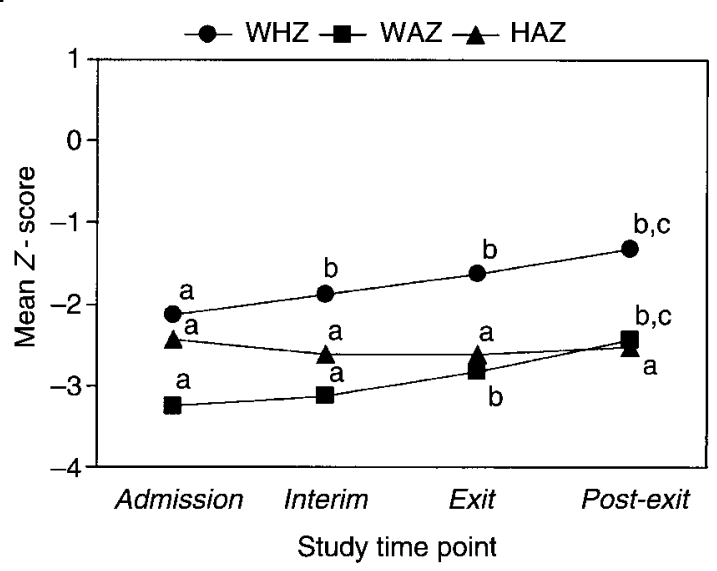

Fig. 3 Mean anthropometric indices (WHZ, weight-for-height $Z$ score; WAZ, weight-for-age Z-score; HAZ, height-for-age Z-score) from admission to post-exit of Ghanaian children participating in nutrition rehabilitation centres. Means on a line with different superscripts are significantly different $(P<0.05)$; using one-way analysis of variance and Bonferonni's post hoc comparisons between time points

than children with shorter effective stay $(P<0.05)$. While the overall HAZ did not change, there was a significant increase in HAZ between admission and exit for children who had been officially discharged $(P=0.02)$. Caregiver/ child pairs who were officially discharged had a longer mean effective stay than did those who left the programme unofficially (1.8 \pm 0.4 vs. $1.2 \pm 0.1$ months, respectively; $P=0.03)$. In the linear regression analyses, length of NRC stay was positively associated with both WHZ $(P=0.08)$ and WAZ $(P<0.05)$ at post-exit.

Children who were still breast-fed at admission were younger at post-exit than those weaned (17.3 \pm 0.8 vs. $22.7 \pm 1.3$ months, respectively). The majority (69\%) of these children were still breast-feeding at post-exit and they had lower WHZ and WAZ $(P<0.05)$. However, postexit breast-feeding status did not significantly predict any of the anthropometric outcomes.

\section{Discussion}

An underlying assumption of the NRC educational activities is that caregivers cook for their children. Caregivers' reliance on purchased foods counters this assumption and diminishes the effectiveness of the educational approach. Street foods are an important component of the diet in many communities ${ }^{15}$, and in Ghana the purchase of street foods is common among low-income households ${ }^{16}$. The safety of street foods has received attention ${ }^{17-21}$; less is known about the choice and nutritional quality of street foods purchased for children. Mensah et al. ${ }^{22}$ reported that the type of food and serving method partly determined the microbial quality of purchased foods. The lowest contamination was found with the common weaning food koko, a nutrient-poor cereal porridge. Caregivers need education on how to choose the safest street foods and enhance the nutritional quality of these foods.
Children's home-based diets did not improve with NRC participation. Caregivers perceived the cereals as expensive, inaccessible and requiring extra effort to prepare. The choice of foods used at the centres was dictated by international food aid, an important resource as the centres were not well funded. Nevertheless, use of these foods limited the empowerment of caregivers.

Effective growth monitoring for assessing progress during rehabilitation requires that children be weighed daily $^{23}$; however, this was not practised. While most study children gained weight while attending the NRC, their mean WHZ at exit $(-1.6 \pm 0.1 \quad Z$-score $)$ fell considerably short of the World Health Organization's (WHO) recommended anthropometric discharge criterion (WHZ $\geq-1.0 Z$-score $)^{23}$. This difference was not due to mothers leaving the programme voluntarily; children who were officially discharged had similar exit WHZ to those leaving the programme unofficially $(-1.7 \pm 0.2$ vs. $-1.6 \pm 0.1 Z$-score, respectively). Official discharge was based on improvement in weight and the nutrition officer's confidence in the caregiver's ability to provide an adequate diet. An NRC programmatic policy to institute the WHO-recommended anthropometric discharge criteria may help ensure adequate recuperation of children and provide a basis for goal setting with caregivers to enhance their motivation and participation in the recuperation process. The NRC used the weightfor-age growth chart to plot children's weights weekly. Establishing a discharge criterion based on WHZ would require additional resources and further training for NRC personnel in measuring lengths/heights and accurate plotting.

While we did not expect the children's HAZ to improve between admission and exit, there was sufficient time lapse between admission and post-exit (approximately 6 months) for improvement. For the majority of a group of malnourished West Indian children, catch-up growth in length occurred only after they had achieved at least $85 \%$ recovery in their weight-for-length deficits ${ }^{24}$. The fact that the majority of our children did not attain this improvement in WHZ, even by post-exit, may explain the lack of gain in HAZ.

Other researchers have reported that attendance variables were associated with improvements in anthropometry. In Guatemala and Haiti, effective stay was a predictor of increase in weight-for-age percentile during NRC participation ${ }^{8}$. In Jamaica, severely malnourished children who experienced full nutritional rehabilitation in a hospital setting achieved and maintained significant advantages in weight and length for almost 2 years after the intervention, compared with children who were discharged early ${ }^{25}$. Thus, improving attendance and retention of caregivers is likely to enhance successful recuperation of their children. Additionally, improving attendance may also lead to more timely medical referrals and help reduce the high mortality rate (11\%). 
Improving attendance and retention may require restructuring of the programme to address barriers such as work and lack of time. A combined supplementary feeding and food distribution programme could include appointment days for supplementary feeding and education at the centres, and days for food distribution for home use, although dilution of the supplement within the family may occur. Bijlsma and McClean $^{26}$ reported improved nutritional status in the majority of malnourished children who participated in a take-home feeding programme. Home- or community-based programmes could also reduce the time costs of NRC attendance; process evaluations of community-based nutrition education and rehabilitation programmes in Viet Nam are promising ${ }^{27}$. In Bangladesh, domiciliary care by trained health workers after 1 week of day-care NRC treatment was more cost-effective than either inpatient or full daycare treatment ${ }^{28}$. This approach is time-saving for caregivers and health worker-caregiver interactions could lead to early identification and intervention for children in decline because of infections, feeding problems or detrimental cultural practices. A combination of efforts, appropriate for local conditions and resources, is needed to address the issue of poor NRC attendance.

While poor attendance was partly responsible for the inadequate gains in growth, other programme factors may have played a role. The energy content of lunches served at the NRCs met the WHO recommendation of at least $1 \mathrm{kcalg}^{-1}$ for mixed local diets ${ }^{23}$; however, the energy content of breakfasts ranged from 0.3 to $0.6 \mathrm{kcal} \mathrm{g}^{-1}$. The WHO recommendation is based on the assumption that a child receives three meals a day and a fortified formula mix 2-3 times a day. No supplemental formula was provided for the children at any of the centres and two of them did not provide a mid-morning snack. The NRC therefore did not provide the energy and protein necessary for the desired accelerated rates of catch-up growth ${ }^{29}$. Poor funding was a key factor determining food availability; thus improving the programme would require additional funding. If caregivers could see timely improvement in their children's growth, they may be less likely to consider a spiritual cause and remove the child from the NRC to use traditional healers. Better interactions between caregivers and NRC personnel and meaningful discussions on the causes of PEM may also help curb harmful cultural practices.

Children who were breast-feeding at admission were less likely to show anthropometric improvement at postexit. It is unlikely that this outcome was due to reverse causality $^{30}$, because the children who were still breastfeeding at admission had similar anthropometric indices to those not breast-feeding. At post-exit the percentage of eating events that comprised koko tended to be higher for the breast-fed children than for those who were weaned (40\% vs. 26\%; $P=0.065$ ). Recently, Marquis et $a l .{ }^{31}$ reported that breast-feeding Ghanaian children were significantly more likely to receive paps (primarily $k o k o$ ) as a complementary food than weaned children. This may reflect maternal perceptions of breast-fed children as 'still young' and, therefore, still fed as an infant. Koko, without enrichment, is low in energy, protein and micronutrients, and we found significant inverse associations between koko consumption and post-exit WAZ and HAZ $(P<0.01)$. Morbidity was not assessed between exit and post-exit, limiting the interpretation for the differences. Caregivers attending an NRC may require additional education on appropriate food choices for complementary feeding while breast-feeding.

An important limitation of the study was the lack of a control group to strengthen the cause-effect link between NRC participation and children's growth. Given the positive associations between attendance and anthropometry, NRC participation probably enhanced children's growth. This conclusion is tempered by the possibility that caregiver characteristics are confounding factors and associated with attendance and growth outcomes. Additionally, the high loss to follow-up diminished the sample size and may have introduced selection bias. Although we found no significant differences between caregivers and children who dropped out and those who continued attending the NRCs, all differences might not have been captured by the data instruments.

This study served to document the growth of children participating in NRCs in Accra, Ghana and uncovered several programme limitations. These limitations include poor attendance and retention, dissonance between NRC educational assumptions and caregivers' child-feeding realities, and sub-optimal supplemental feeding. This research has provided information and recommendations that can guide policy decisions to improve or change the NRC programme. Furthermore, the study identified street foods as an important area for research, particularly with respect to the choice of street foods provided for children and their impact on children's nutritional status.

\section{Acknowledgements}

We wish to thank Ms Akweley and Mr Nortey of the Ghana Ministry of Health for their assistance in starting up the study and training fieldworkers. We also thank the leadership of the polyclinics for their co-operation and receptiveness towards the study. The nutrition officers and their aides at the NRCs are fondly acknowledged for their welcome and assistance. We are grateful to the study participants for their willingness to participate and for the hospitality they extended to study staff during home visits. We also acknowledge with gratitude the hard work and diligence of Miss Dede Oracca-Tetteh and the fieldworkers whose tireless efforts in recruiting and following up study participants contributed greatly to the success of this project. The project was funded in part by the Sparkman 
Centre for Public Health Education at the University of Alabama at Birmingham.

\section{References}

1 United Nations Children's Fund (UNICEF). The State of the World's Children. New York: Oxford University Press, 2000.

2 De Onis M, Frongillo EA, Blossner M. Is malnutrition declining? An analysis of changes in levels of child malnutrition since 1980. Bulletin of the World Health Organization 2000; 78: 1222-33.

3 Government of Ghana/United Nations Children's Fund (UNICEF). Situation of Women and Children in Ghana. Joint Report. Accra: Government of Ghana and UNICEF, 2000

4 Ghana Statistical Services. Demographic and Health Survey. Accra: Ghana Statistical Services, 1998.

5 World Health Organization. Global Database on Child Growth and Malnutrition. Available at http://www.who.int/ nutgrowthdb. Accessed 30 January 2003.

6 Bengoa JM. Nutrition rehabilitation centres. Journal of Tropical Pediatrics 1967; 13: 169-76.

7 Osei-Boateng M. Nutrition rehabilitation in the promotion of child health in Ghana. International Nursing Review 1979; 26: $133-6$.

8 Beaudry-Darisme M, Latham MC. Nutrition rehabilitation centres; an evaluation of their performance. Journal of Tropical Pediatrics and Environmental Child Health 1973; 19: 299-332.

9 Ojofeitimi EO, Teniola SO. Evaluation of the nutrition rehabilitation centre in Ife-Ife, Oyo State, Nigeria. World Review of Nutrition and Dietetics 1980; 35: 87-95.

10 Perra A, Costello AM. Efficacy of outreach nutrition rehabilitation centres in reducing mortality and improving nutritional outcome of severely malnourished children in Guinea Bissau. European Journal of Clinical Nutrition 1995; 45: 353-9.

11 Reneman L, Derwig J. Long-term prospects of malnourished children after rehabilitation at the nutrition rehabilitation centre of St. Mary's Hospital, Mumias, Kenya. Journal of Tropical Pediatrics 1997; 43: 293-6.

12 Gomes do Monte CM, Ashworth A, Sa ML, Diniz RL. Effectiveness of nutrition centres in Ceara State, northern Brazil. Revista Panamerica de Salud Publica 1998; 4: 375-82.

13 Thompson FE, Byers T. Dietary assessment resource manual. Journal of Nutrition 1994; 124: 2245S-317S.

14 Patton MQ. Qualitative Evaluation and Research Methods, 2nd ed. Newbury Park, CA: Sage Publications, 1990.

15 Food and Agriculture Organization (FAO). Street Foods. Report of an FAO Technical Meeting on Street Foods. Rome: FAO, 1997.

16 Maxwell D, Levin C, Armar-Klemesu M, Ruel M, Morris S, Ahiadeke C. Urban Liveliboods and Food and Nutrition Security in Greater Accra, Ghana. Research Report 112 Washington, DC: International Food Policy Institute in collaboration with Ngouchi Memorial Institute and the World Health Organization, 2000.

17 Garin B, Ajdara A, Spiegel A, Arrive P, Bastaraud A, Cartel JL, et al. Multicenter study of street foods in 13 towns on four continents by the food and environmental hygiene study group of the international network of Pasteur and associated institutes. Journal of Food Protection 2002; 65: 146-52.

18 Mathee A, Von Schirmding YE, Byme J, De Beer M, Letlape A, Hobbs C, et al. The greater Johannesburg healthy foods/markets programme. Urban Health Newsletter 1996; 28: 39-47.

19 Bhat RV, Waghray K. Street foods in Africa. World Review of Nutrition and Dietetics 2000; 86: 100-22.

20 King LK, Awumbila B, Canacoo EA, Ofosu-Armah S. An assessment of the safety of street foods in Ga district of Ghana; implications for the spread of zoonoses. Acta Tropica 2000; 76: 39-43.

21 Enakem EE, Adedeji OT, Akitoye CO. Environmental and behavioural risk factors for prolonged diarrhoea in Nigerian children. Journal of Diarrhoeal Diseases Research 1994; 12: $19-24$

22 Mensah P, Yeboah-Manu D, Owusu-Darko K, Ablordey A. Street foods in Ghana: how safe are they? Bulletin of the World Health Organization 2002; 80: 547-54.

23 World Health Organization (WHO). Management of Severe Malnutrition: A Manual for Physicians and Other Senior Health Workers. Geneva: WHO, 1999.

24 Walker SP, Golden MH. Growth in length of children recovering from severe malnutrition. European Journal of Clinical Nutrition 1988; 42: 395-404.

25 Heikens GT, Schofield WN, Dawson SM, Waterlow JC. Longstay versus short-stay hospital treatment of children with severe protein-energy-malnutrition. European Journal of Clinical Nutrition 1994; 48: 873-82.

26 Bijlsma M, McClean D. Assessment of a take home child supplementary feeding program in a high density suburb of Mutare City, Zimbabwe. Central African Journal of Medicine 1997; 43: 16-20.

27 Dickey VC, Pachon H, Marsh DR, Lang TT, Claussenius DR, Dearden KA, et al. Implementation of nutrition education and rehabilitation programs (NERPs) in Viet Nam. Food and Nutrition Bulletin 2002; 23: 75-82.

28 Ashworth A, Khanum S. Cost-effective treatment for severely malnourished children: what is the best approach? Health Policy and Planning 1997; 12: 115-21.

29 Ashworth A. Practical aspects of dietary management during rehabilitation from severe protein energy malnutrition. Journal of Human Nutrition 1980; 34: 360-9.

30 Marquis GS, Habicht JP, Lanata CF, Black RE, Rasmussen KM. Association of breastfeeding and stunting in Peruvian toddlers: an example of reverse causality. International Journal of Epidemiology 1997; 26: 349-56.

31 Marquis GS, Penny ME, Colecraft EK, Lozada MF. A comparison of patterns of breastfeeding and complementary feeding in Peru and Ghana. In: Pickering LK, Morrow AL, Schanler RJ, Ruiz-Palacios GM, eds. Protecting Infants through Human Milk: Advancing the Scientific Evidence Base. New York: Kluwer Publishers, 2003; in press. 